www.jmscr.igmpublication.org

Index Copernicus Value: 79.54

ISSN (e)-2347-176x ISSN (p) 2455-0450

crossref DOI: https://dx.doi.org/10.18535/jmscr/v7i5.153

Journal Of Medical Science And Clinical Research

IGM Publication

An Official Publication of IGM Publication

\title{
Correlation between Central Corneal thickness and Intraocular Pressure measured with Goldmann Applanation Tonometer (GAT) in healthy individuals
}

\author{
Author \\ Dr Shazia Qayum \\ MS Ophthalmology DNB Ophthalmology \\ Assistant Professor, GMC Rajouri (Incharge Head)
}

\begin{abstract}
Introduction: Intraocular pressure (IOP) measurement is one of the vital and most commonly performed examination in ophthalmology. Goldmann applanation tonometer (GAT) has been labelled as gold standard for measurement of Intraocular pressure. IOP measurement is known to be affected by Central corneal thickness (CCT). It has been stated that thinner corneas leads to false low IOP interpretations while thicker corneas leads to false high IOP interpretations, thus causing apparent normal tension glaucoma (NTG) and ocular hypertension (OHT) respectively.

Objective: To evaluate the effect of CCT on IOP readings by Goldmann Applanation Tonometry in healthy individuals

Methodology: This prospective study included 200 eyes of 100 patients attending the outpatient department of ophthalmology, from January 2018 to June 2018, in MMIMSR, Mullana. The patients included were devoid of any corneal disorder, history of antiglaucoma medications, keratitis, keratoconus, corneal scar, corneal dystrophy and degeneration. A total number of 200 eyes were investigated using the Ultrasonic

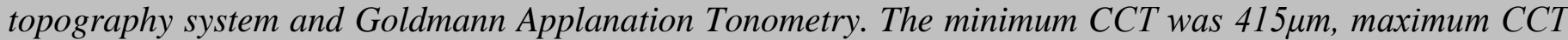
was $648 \mu \mathrm{m}$ with mean CCT being $528.5 \mu \mathrm{m}$ with $S D \pm 29.48 \mu \mathrm{m}$. The minimum IOP recorded was $9 \mathrm{mmHg}$, maximum IOP was $22 \mathrm{mmHg}$ and mean IOP was $14.92 \mathrm{mmHg}$ with $\mathrm{SD} \pm 2.98 \mathrm{mmHg}$

Conclusion: In our study, we found that Central corneal thickness was correlated with intraocular pressure significantly in both men and women. Athick cornea leads to an overestimation of IOP while thin cornea leads to an underestimation of IOP.

Keywords: Central corneal thickness, Intraocular pressure, Goldmann Applanation Tonometer, pachymetry, Glaucoma.
\end{abstract}

\section{Introduction}

Intraocular pressure (IOP) measurement is one of the vital and most commonly performed examination in ophthalmology. Goldmann applanation tonometer (GAT) has been labelled as gold standard for measurement of Intraocular pressure. IOP measurement is known to be affected by Central corneal thickness $(\mathrm{CCT})^{1,2}$ The GAT is based on Imbert-Fick law which states that an external force against a sphere equals the pressure in the sphere times the area flattened by the external force. However, the 
rationality of this law needs that the sphere is exactly spherical and flexible, dry and extremely thin. But the cornea fails to gratify any of these requirements as it is aspherical and wet and neither flexible nor markedly thin. The moisture generates surface tension, while the lack of flexibility needs force that is not dependent of the internal pressure to mold the cornea. These forces balance each other for the GAT (applanation diameter of $3.06 \mathrm{~mm}$ ) when the CCT is $520 \mu \mathrm{m}$, providing a "reference" value where the applanating pressure does equal the $\mathrm{IOP}^{3}$ Goldmann based his notion of tonometry on a modification of this law and found that ocular rigidity does not significantly influence the measurement of IOP. However, corneal variables, contact duration, semicircles of Goldmann tonometry, and calibration may influence the results. A thicker cornea needs greater force to applanate and on the other hand, a thinner cornea gets easily flattened. Athin cornea is a important risk factor for the development of glaucoma ${ }^{4}$.Various studies have been done to correlate the relationship between IOP measured by GAT and $\mathrm{CCT}^{4,5}$ however it was Ehlers et al ${ }^{1}$ and Whitacre et $\mathrm{al}^{2}$ who measured IOP by manometer. It has been stated that thinner corneas leads to false low IOP interpretations while thicker corneas leads to false high IOP interpretations, thus causing apparent normaltension glaucoma (NTG) and ocular hypertension (OHT) respectively ${ }^{6}$. With the advent of PRK (photorefractive keratectomy) in myopia, there is underestimation of IOP as PRK causes thinning of central cornea ${ }^{7,8}$. Ultrasonicpachymetry is the most frequently used method for measuring CCT however various sophisticated methods have been recently used one of them being non-contact Scanning Slitbased (Orbscan) pachymetry. In this study we evaluated the effect of CCT on IOP readings by GAT in healthy individuals.

\section{Methodology}

This prospective study included 200 eyes of 100 patients attending the outpatient department of ophthalmology, from January 2018 to June 2018, in MMIMSR, Mullana. The patients included were devoid of any corneal disorder, history of antiglaucoma medications, keratitis, keratoconus, corneal scar, corneal dystrophy and degeneration. Out of 100 patients, 54 were females and 46 were males.

The age range of patients was 14 years- 60 years with mean age was 29.32 years with standard deviation $(\mathrm{SD}) \pm 7.45$ years. A total number of 200 eyes were investigated using the Ultrasonic topography system and Goldmann Applanation Tonometry. The minimum CCT was $415 \mu \mathrm{m}$, maximum CCT was $648 \mu \mathrm{m}$ with mean CCT being $528.5 \mu \mathrm{m}$ with $\mathrm{SD} \pm 29.48 \mu \mathrm{m}$. The minimum IOP recorded was $9 \mathrm{mmHg}$, maximum IOP was $22 \mathrm{mmHg}$ and mean IOP was 14.92 $\mathrm{mmHg}$ with $\mathrm{SD} \pm 2.98 \mathrm{mmHg}$. In this study 46 patients (92eyes) were males. The minimum CCT in male patients was $421 \mu \mathrm{m}$, maximum CCT was $632 \mu \mathrm{m}$ and mean CCT was $527.02 \mu \mathrm{m}$ SD \pm $28.19 \mu \mathrm{m}$. The minimum IOP was $9 \mathrm{mmHg}$, maximum IOP was $20 \mathrm{mmHg}$ and mean IOP was $14.96 \mathrm{mmHg} \mathrm{SD} \pm 2.89 \mathrm{mmHg}$. Out of 100 patients, 54 were females. The minimum CCT of female patients was $415 \mu \mathrm{m}$, maximum CCT was $648 \mu \mathrm{m}$ and mean CCT was $532.15 \mu \mathrm{m}$ SD \pm $34.21 \mu \mathrm{m}$. The minimum IOP was $10 \mathrm{mmHg}$, maximum IOP was $21 \mathrm{mmHg}$ and mean IOP was $15.43 \mathrm{mmHg} \mathrm{SD} \pm 2.98 \mathrm{mmHg}$. The patients were divided into various groups according to $\mathrm{CCT}$ and IOP and are depicted in Table no.1

Table No.1 CCT and IOP in different age groups

\begin{tabular}{|l|c|c|c|c|}
\hline GROUPS & $\begin{array}{c}\text { CENTRAL CORNEAL } \\
\text { THICKNESS }\end{array}$ & \multicolumn{2}{c|}{$\begin{array}{c}\text { INTRAOCULAR } \\
\text { PRESSURE BY } \\
\text { GAT(mm Hg) }\end{array}$} \\
\hline & \multicolumn{2}{|c|}{$\begin{array}{c}\text { NO. of eyes(n) } \\
\text { Mean }\end{array}$} & \multicolumn{2}{c|}{$\begin{array}{c}\text { No.of eyes(n) } \\
\text { Mean }\end{array}$} \\
\hline $\begin{array}{l}410-439 \\
\mu \mathrm{m}\end{array}$ & 05 & $432.95 \mu \mathrm{m}$ & 05 & 10.43 \\
\hline $440-469 \mu \mathrm{m}$ & 06 & $459.73 \mu \mathrm{m}$ & 06 & 11.65 \\
\hline $470-499 \mu \mathrm{m}$ & 28 & $492.78 \mu \mathrm{m}$ & 28 & 12.52 \\
\hline $500-529 \mu \mathrm{m}$ & 80 & $522.65 \mu \mathrm{m}$ & 80 & 14.63 \\
\hline $530-569 \mu \mathrm{m}$ & 68 & $556.45 \mu \mathrm{m}$ & 68 & 15.54 \\
\hline $570-599 \mu \mathrm{m}$ & 08 & $580.29 \mu \mathrm{m}$ & 08 & 16.64 \\
\hline $600-629 \mu \mathrm{m}$ & 03 & $610.34 \mu \mathrm{m}$ & 03 & 19.23 \\
\hline $630-669 \mu \mathrm{m}$ & 02 & $649.00 \mu \mathrm{m}$ & 02 & 21.00 \\
\hline
\end{tabular}




\section{Discussion}

There are numerous studies on the relationship between CCT and $\mathrm{IOP}^{9-12}$. Some studies done showed significant relationship between CCT and IOP as reported by Wolfs et al and Herndon et al. However, in a study conducted by Lam and Douthwaite on Chinese subjects in the age group 19-23 years showed no significant relationship between CCT and IOP. This study of ours reported a statistically significant positive correlation between CCT and IOP. The IOP is an vital functional parameter for the diagnosis and management of glaucoma. Goldmann applanation tonometry is one of the most frequent method used for calculating IOP, however numerous aspects such as tear film, shape of the anterior cornea, corneal thickness or scleral rigidity can effect its precision in healthy individuals. It has been proposed that CCT is a main source of error in applanation tonometry ${ }^{13,14}$, a thick cornea causing an overestimation of IOP and a thin cornea causing an underestimation ${ }^{1,15,16}$.

Numerous studies endorses a correlation between central corneal thickness and false IOP readings. In a study conducted by Johnson and coauthors ${ }^{17}$ in a 17-year-old girl with an IOP of 30to $40 \mathrm{~mm}$ $\mathrm{Hg}$ with standard visual fields and optic nerve heads in both eyes and failed medical management reported the central corneal thickness of was $900 \mu \mathrm{m}$ in both eyes without corneal edema. On Manometry of left eye, IOP recorded was $11 \mathrm{~mm} \mathrm{Hg}$; while the IOP measured with Perkins and Schiotz tonometers was 35 and $34 \mathrm{~mm} \mathrm{Hg}$, respectively. In our study, the mean IOP for both sexes combined to be $14.92 \mathrm{mmHg}$. However, the mean IOP was $15.8 \mathrm{mmHg}$ in Icelandic population survey which used Schiötz tonometry ${ }^{18}$ and to the $15.2 \mathrm{mmHg}$ in a study done by Klein et al., who surveyed using Goldmann applanation tonometry ${ }^{19}$. The mean IOP in females and males in our study was 15.43 $\mathrm{mmHg}$ and $14.96 \mathrm{mmHg}$ respectively. This resultwas comparable to the several large population samples surveyed using Goldmann applanation tonometry ${ }^{20}$. Mean CCT we found was $528.5 \mu \mathrm{m}$ for both males and females. In a study done on Japanese population showed mean CCT of $517.5 \mu \mathrm{m}$.

\section{Conclusion}

In our study, we found that Central corneal thickness was correlated with intraocular pressure significantly in both men and women. A thick cornea leads to an overestimation of IOP while thin one leads to an underestimation of IOP. There was no significant difference in central corneal thickness and intraocular pressure between the right and left eyes or between male and female subjects.

\section{References}

1. Ehlers N, Bramsen $\mathrm{T}$, Sperling $\mathrm{S}$. Applanation tonometry and central corneal thickness. Acta Ophthalmol. 1975; 53: 3443.

2. Whiotacre MM, Stein RA, Hassanein K. The effect of corneal thickness on applanation tonometry. Am J Ophthalmol. 1993;115: 592-6.

3. Gordon MO, Beiser JA, Brandt JD, et al. The ocular hypertension treatment study: baseline factors that predict the onset of primary open-angle glaucoma. Arch Ophthalmol. 2002; 120: 714-20

4. Kruse-Hansen F, Ehlers N. Elevated tonometry readings caused by thick cornea. Acta Ophthalmol. 1971; 49: 775-8.

5. Ehlers N, Kruse-Hansen. Central corneal thickness in low tension glaucoma. Acta Ophthalmol. 1974; 52: 740-6.

6. Copt RP, Thomas R, Mermoud A. Corneal thickness in ocular hypertension, primary open-angle glaucoma and normal tension glaucoma. Arch Ophthalmol. 1999; 117: 14-6.

7. Binder PS, Bosem M, Weinreb RN. Scheimpflug anterior segment photography assessment of wound healing after myopic excimer laser photorefractive 
keratectomy. J Cataract Refract Surg. 1996; 22: 205-12.

8. Lattimore MR, Kaupp S, Schallhorn S, et al. Orbscan pachymetry: implications of a repeated measures and diurnal variation analysis. Ophthalmology 1999; 106: 97781

9. Foster PJ, Baasanhu J, Alsbirk PH, et al. Central corneal thickness and intraocular pressure in a mongolian population. Ophthalmology. 1998; 105: 969-73.

10. Wolfs RCW, Klaver CCW, Vingerling JR, et al. Distribution of central corneal thickness and its association with intraocular pressure: The Rotterdam Study. Am J Ophthalmol. 1997; 123:767-72.

11. Lam AKC, Douthwaite WA. The effect of an artificially elevated intraocular pressure on corneal thickness in Chinese eye. OphthalmolPhysiol Opt. 1997; 17: 414-9.

12. Herndon LW, Choudhri SA, Cox T, et al. Central corneal thickness in normal, glaucomatous, and ocular hypertensive eyes. Arch Ophthalmol. 1997; 115: 113741.

13. Whiotacre MM, Stein RA. Sources of error with use of Goldmann-type tonometers. SurvOphthalmol. 1993; 38: 1-30.

14. Shah S. Accurate intraocular pressure measurement: The myth of modern ophthalmology? Ophthalmology. 2000; 107: $1805-7$

15. Shields M. Textbook of Glaucoma, 3rd ed. Baltimore: Williams and Wilkins, 1992.

16. Doughty MJ, Zamam ML. Human corneal thickness and its impact on intraocular pressure measures: A review and metaanalysis approach. SurvOphthalmol. 2000; 44: 367-408.

17. Johnson M, KassMA,Moses RA, Grodzki WJ. Increased corneal thickness simulating elevated intraocular pressure. Arch Ophthalmol 1978; 96:664-665
18. Bjornsson G. The primary glaucoma in Iceland: epidemiological studies. Acta Ophthalmol Supplement. 91: 68- 9.

19. Klein BE, Klein R, Sponsel WE, et al. Prevalence of glaucoma. The Beaver Dam Eye Study. Ophthalmol. 1992; 99: 14991504.

20. Hollows FC, Graham PA. Intra-ocular pressure, glaucoma and glaucoma suspects in a defined population. $\mathrm{Br} \mathrm{J}$ Ophthalmol.1996; 50: 570-86. 